\title{
Characterization of Silver Nanoparticles Synthesized Using Ocimum basilicum Seed Extract
}

\author{
Mahalakshmi Lakshmanan ${ }^{1 \mathbb{D}}$, Dharani Ragul ${ }^{1}{ }^{(\mathbb{D}}$, Maria Leena Michael ${ }^{1}{ }^{(\mathbb{D}}$, Jeyan Arthur Moses ${ }^{1(\mathbb{D})}$, \\ Chinnaswamy Anandharamakrishanan 1,* (D) \\ 1 Computational Modeling and Nanoscale Processing Unit, Indian Institute of Food Processing Technology (IIFPT), \\ Ministry of Food Processing Industries, Govt. of India, Thanjavur, Tamil Nadu \\ * Correspondence: anandharamakrishnan@iifpt.edu.in (C.A.);
}

Received: 30.07.2021; Revised: 25.08.2021; Accepted: 28.08.2021; Published: 4.09.2021

\begin{abstract}
The development of an eco-friendly method for the production of nanomaterials is an area of significant research and commercial interest owing to its numerous applications in various disciplines. This study used a simple green synthesis approach to produce silver nanoparticles using Ocimum basilicum seed extract. The optical, structural, and morphological characteristics of the synthesized silver nanoparticles (Ag NPs) were found using UV visible absorption spectroscopy, Fourier transform infrared spectroscopy (FTIR), X-Ray diffractometer (XRD), dynamic light scattering (DLS), field emission scanning electron microscope (FE-SEM), and energy dispersive X-ray analysis (EDAX). The aqueous medium containing reduced silver ions showed maximum UV absorption at 430 $\mathrm{nm}$ in response to the plasmon absorbance behavior of silver nanoparticles. Synthesized nanoparticles had a spherical shape with an average particle size of $134.04 \mathrm{~nm}$ and a face-centered cubic (FCC) structure. Synthesized Ag NPs showed excellent free radical scavenging activity as evaluated using the DPPH method. Additionally, the green synthesized silver nanoparticles showed appreciable antimicrobial activity against gram-positive (Staphylococcus aureus) and gram-negative (Escherichia coli) bacteria compared to $O$. basilicum seed extract. Thus, $O$. basilicum seed extract can be used as a bio-reducing agent for producing silver nanoparticles and an effective way of using bioactive resources with their medicinal benefits.
\end{abstract}

Keywords: silver nanoparticles; green synthesis; Ocimum basilicum; antimicrobial; antioxidant nanoparticles.

(C) 2021 by the authors. This article is an open-access article distributed under the terms and conditions of the Creative Commons Attribution (CC BY) license (https://creativecommons.org/licenses/by/4.0/).

\section{Introduction}

Metal nanoparticles have unique properties owing to their large surface area to volume ratio, a large fraction of surface atoms, surface plasmon resonance behavior, spatial confinement of electrons, surface energy, and crystalline nature with low imperfections and differ significantly from their respective bulk materials $[1,2]$, Such unique properties have enabled them to be appropriate candidates for a variety of applications including catalysis [3], biosensing [4], drug delivery [5], food science [6], water purification [7], electrochemical sensing [8], agriculture [9], nanodevice fabrication [10], amongst others.

Among the various noble metals, silver (Ag) exhibits remarkable antimicrobial, antiviral and biocompatible properties, showing promising potential for biomedical applications and those involving microbial resistance, sunscreen lotions, molecular imaging contrast agent, DNA detection, wound healing, drug delivery, diagnostic and treatment of 
diseases, and food packaging $[11,12]$. The structure, morphology, and composition of silver nanoparticles (Ag NPs) are unique; Ag NPs linked with the thiol group present in respiratory enzymes of a bacterial cell can inhibit the respiratory process and lead to cell death [13].

Different approaches have been reported to synthesize Ag NPs, including chemical reduction, high energy radiation-induced reduction, and biological methods. Nevertheless, it is well regarded that the biological approach is biocompatible and eco-friendly, and free from biological risks [14].

Green synthesis of Ag NPs has been reported using a broad range of plant extracts, microorganisms, and other bio-based sources [15-17]. A non-exhaustive list of recent studies reporting the synthesis of Ag NPs from various plant extracts and their properties [18-24]. Among the different biological sources, plant extracts are easily available, safe, biocompatible, and provide good control over morphology and stability [12]. Ocimum basilicum seed belonging to the Lamiaceae family is an edible ornamental herb grown in tropical and subtropical countries, valued for its phytochemical, nutritional, and health benefits $[25,26]$. The formation of a mucilaginous gel around the epicarp of the seeds, when soaked in water, is a characteristic property. In traditional medicine, O. basilicum has been used to treat colic ulcers, dyspepsia, inflammations, relieve indigestion, sore throat, diarrhea, weight loss, constipation, and diabetes [27, 28]. Also, O. basilicum seeds are known to have good antimicrobial, antioxidant, and anticancer properties [26, 29].

This study focuses on synthesizing Ag NPs using basil seed extract and assess their antimicrobial and antioxidant capabilities. In the green synthesis method, proteinous materials and phytochemicals such as flavonoids, phenolics, saponins, tannins, and alkaloids reduce Ag ions from the precursor [30, 31]. Further, the optical, structural, morphological, and elemental characteristics of biosynthesized Ag NPs have been characterized in detail.

\section{Materials and Methods}

\subsection{Chemicals.}

Basil seed (O. basilicum) was procured from a local market in Thanjavur, Tamil Nadu, India. Silver nitrate $\left(\mathrm{AgNO}_{3}\right)$ was obtained from Sigma-Aldrich, USA. Double-distilled water was used for all experiments, and all the experiments were carried out in triplicates.

\subsection{Preparation of basil seed extract.}

Using a hand mixer, $20 \mathrm{~g}$ of basil seed was ground and boiled for $1 \mathrm{~h}$ at $60^{\circ} \mathrm{C}$ in $150 \mathrm{ml}$ distilled water. Then, the extract was cooled and filtered. The filtrate was used to reduce $\mathrm{AgNO}_{3}$ and synthesize Ag NPs. The color and translucency of the extract are presented in Figure 1. Samples were stored at $4^{\circ} \mathrm{C}$ until further use.

\subsection{Synthesis of Ag NPs.}

The green synthesis approach was used for the synthesis of Ag NPs using basil seed extract. For this, $1 \mathrm{mM}$ of $\mathrm{AgNO}_{3}$ precursor solution was prepared using double distilled water. Then, $10 \mathrm{ml}$ of basil seed extract was added slowly to the precursor solution. The reaction was kept at $60^{\circ} \mathrm{C}$ under constant stirring. The $\mathrm{pH}$ of the solution was found to be 7.2. The sample was collected at every 10 minutes interval. After 20 minutes, the color change (from colorless to reddish-brown) was observed, indicating the formation of Ag NPs. 


\subsection{Characterization of biosynthesized Ag NPs.}

Preliminary confirmation of the bioreduction of $\mathrm{AgNO}_{3}$ to $\mathrm{Ag}$ ion in an aqueous medium was performed using the UV-visible absorption spectrum of the solution obtained at different time intervals. The UV-visible absorption spectrum was obtained from 200 to $700 \mathrm{~nm}$ at a resolution of $1 \mathrm{~nm}$ using a UV-vis spectrophotometer (UV 1800, Shimadzu Scientific Instruments Inc., Japan). Distilled water was used as a blank for this study. Ag NPs on the solution were washed with ethanol by centrifugation and dehydrated for $12 \mathrm{~h}$ in a hot air oven at $60^{\circ} \mathrm{C}$ and subjected to further characterization. Chemical analysis was carried out by placing the dehydrated samples in attenuated FTIR sample holders and obtaining the transmittance spectrum in the wavelength ranging from $4000-400 \mathrm{~cm}^{-1}$ at $4 \mathrm{~cm}^{-1}$ resolution using an FT-IR spectrometer (Spectrum Two, PerkinElmer, Inc., Japan) averaging 60 scans. The average particle size, PDI (Poly Dispersity Index), and zeta potential of green synthesized nanoparticles were characterized using a Zeta sizer nano-series (Malvern ZS90, Malvern Instruments Ltd, UK) after dispersing synthesized Ag NPs in water by ultra sonicator. The crystal structure and phase purity of synthesized Ag NPs were analyzed using an X-ray diffractometer (D8 Focus, Bruker, Germany). The average crystal size was determined using the following Debye Scherrer's equation [32].

$$
\mathrm{D}=\mathrm{K} \lambda / \beta \cos 2 \theta
$$

where $D$ is the crystallite size $(\mathrm{nm}), \lambda$ is the wavelength of the $X$-ray radiation, $K(=0.9)$ is the crystallite-shape factor, $\beta$ is the full width at half maximum of the diffraction peak and $\theta$ is the diffraction angle.

The morphology of synthesized Ag NPs was analyzed using Field Emission Scanning Electron Microscopy (FE-SEM) on a JEOL microscope (JEOL 6390, JEOL Inc., Peabody, MA, USA) at an accelerated voltage of $20 \mathrm{kV}$. Previously, the dried Ag NPs were placed on the sample holding stub using carbon double side adhesive tape and sputtered with gold using a vacuum sputter coater (JFC-1600 Auto fine coater, JEOL, Ltd., Tokyo, Japan).

\subsection{Antimicrobial activity.}

The antimicrobial activity of the green synthesized Ag NPs prepared using basil seed extract was assayed by the well diffusion method. The antimicrobial effect of synthesized Ag NPs was checked against pathogenic bacteria Staphylococcus aureus (S. aureus) and Escherichia coli (E. coli). First, the pure bacterial culture was sub-cultured in nutrient broth. Then, the bacterial strain was uniformly spread over the nutrient agar medium using an Lshaped glass rod. Around $6 \mathrm{~mm}$ wells were punctured on the nutrient agar plates. A $50 \mu \mathrm{l}$ of synthesized Ag NPs was poured on the well using a micropipette. The basil seed extract was used as the positive control, and water was used as the negative control. The plates were then incubated for $24 \mathrm{~h}$ at $37^{\circ} \mathrm{C}$. The region of inhibition of bacteria surrounding the well was measured after the incubation period.

\subsection{Antioxidant activity.}

The free radical scavenging activity of the synthesized Ag NPs was studied using the 2,2-diphenyl-1-picrylhydrazyl (DPPH) method. Previously seed extract and synthesized Ag NPs were dehydrated using a refracting window dryer to obtain dry powder [33, 34]. To compare the free radical scavenging activity of synthesized Ag NPs with that of seed extract 
and vitamin C, $1 \mathrm{mg}$ of each sample was added in water and sonicated. Then, $100 \mu \mathrm{l}$ of each sample was kept for reaction with $300 \mu \mathrm{l}$ of $0.1 \mathrm{mM}$ DPPH in methanol solution. For control, $100 \mu 1$ methanol was mixed with $300 \mu 1 \mathrm{DPPH}$ solution. Then, the reaction mixture was kept in an orbital shaker incubator at $37^{\circ} \mathrm{C}$ for 30 minutes under dark conditions. After incubation, the absorbance of each sample was determined at $517 \mathrm{~nm}$ using UV visible absorbance spectroscopy. Methanol was kept as the blank for UV absorption.

\section{Results and Discussion}

\subsection{Characteristics of synthesized Ag NPs.}

Upon adding the basil seed extract to the precursor solution $\left(\mathrm{AgNO}_{3}\right)$, the color changed from colorless to reddish-brown after 20 minutes, explaining the formation of Ag NPs. The preliminary confirmation of the bioreduction of $\mathrm{AgNO}_{3}$ to $\mathrm{Ag}^{+}$ions in an aqueous medium was done using the UV-visible absorbance spectrum of sampled aliquots at different time intervals. The maximum absorbance was observed at $430 \mathrm{~nm}$. Further, the growth of nanoparticles resulted in the color change from dark red to brown. These color changes occur due to excitation and the surface plasmon resonance behavior of Ag NPs [35]. It was observed that there was no significant color change after 90 minutes, indicating the completion of the bioreduction reaction (Figure 1). The UV-visible spectrum of samples withdrawn at different time intervals is shown in Figure 2. The peak obtained at $430 \mathrm{~nm}(\lambda \max )$ relates to the maximum absorbance of Ag NPs [36, 37]. The intensity of the peak increased with incubation time, indicating the increase in absorbance at the maximum wavelength $(430 \mathrm{~nm})$ as a function of time. The bandgap energy for the synthesized Ag NPs was found to be $2.91 \mathrm{eV}$, corresponding to the obtained wavelength according to Eq. 2 [38].

$$
\mathrm{E}=\mathrm{hc} / \lambda
$$

Eq. 2

where E represents bandgap energy, $\mathrm{h}$ is Planck's constant, $\mathrm{c}$ is the speed of light, and $\lambda$ is the maximum wavelength of the absorption peak.

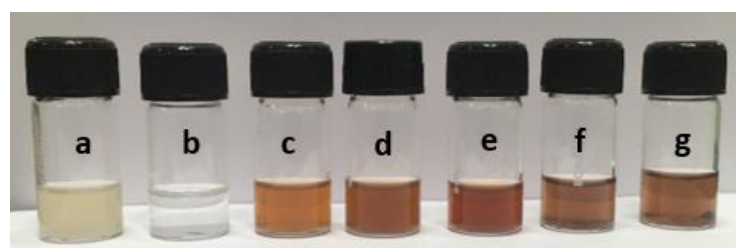

Figure 1. Biosynthesis of Ag NPs (a) basil seed extract; $\mathrm{AgNO}_{3}$ solution added with basil seed extract at different time intervals: (b) 0 minute; (c) 30 minutes; (d) 40 minutes; (e) 50 minutes; (f) 60 minutes, and (g) 90 minutes.

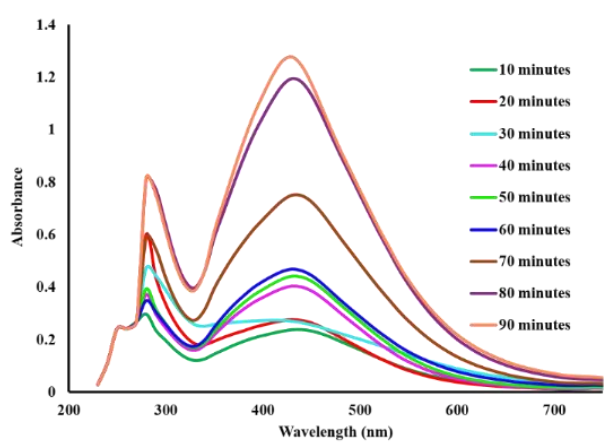

Figure 2. UV visible absorption spectra of biosynthesized Ag NPs at different time intervals. 
Further, the FTIR data (Figure 3) reveals that absorption bands at 3340, 2930, 1590, and $1415 \mathrm{~cm}^{-1}$ are attributed to $\mathrm{O}-\mathrm{H}$ stretching phenol, $\mathrm{C}-\mathrm{H}$ stretching alkane, $\mathrm{N}-\mathrm{H}$ bending amine group, and $\mathrm{C}-\mathrm{H}$ deformation, respectively. The absorption band at $647.53 \mathrm{~cm}^{-1}$ corresponds to $\mathrm{C}-\mathrm{H}$ stretching. Some of these functional groups are related to proteins found in the extract that act as the capping material of the silver nanoparticles and flavonoids in the extract that act as the reducing agent $[39,40]$.

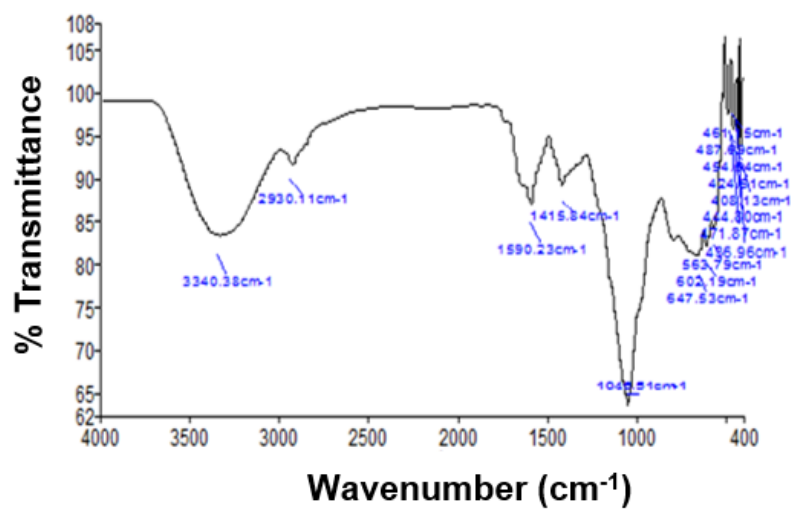

Figure 3. FTIR spectrum for biosynthesized Ag NPs.

The hydrodynamic particle size distribution, PDI, and zeta potential of biosynthesized silver nanoparticles were determined (Figure 4 (a) and 4 (b)). The average particle size, PDI, and zeta potential of the synthesized silver nanoparticles were around $131 \mathrm{~nm}, 0.3$, and -25.7 $\mathrm{mV}$, respectively, at $\mathrm{pH}$ 7.2. This negative value confirms the repulsive effects among the particles. These results indicate that the synthesized particles are fairly stable since the surface potential explains the stability of nanoparticles.

(a)

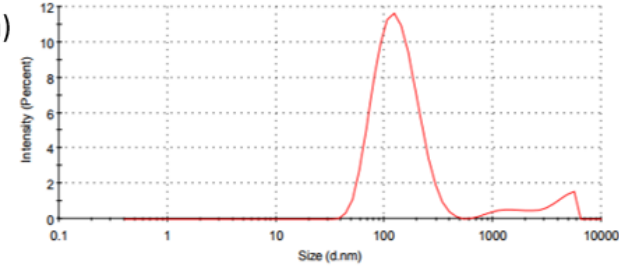

(b)

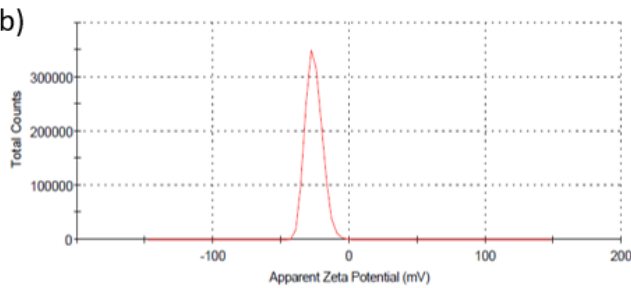

Figure 4. (a) Particle size distribution for biosynthesized Ag NPs; (b) Zeta potential for biosynthesized Ag NPs.

The crystalline nature and average crystal size of the biosynthesized Ag NPs were determined through $x$-ray diffraction analysis (Figure 5). Three distinct diffraction peaks at $38.19^{\circ}, 44.24^{\circ}, 64.43^{\circ}$, and $77.34^{\circ}$ were observed, and these correspond to the index crystalline planes (111), (200), (220), and (311) and indicate the face-centered cubic lattice structure of the silver nanoparticle confirmed with reference number 96-901-1608 [41-43]. The average crystal size of Ag NPs was found to be $6.4 \mathrm{~nm}$ using Debye Scherrer's equation. Some other small peaks were obtained in the XRD pattern, and these might be due to the presence of bioactive compounds over the Ag NP's surface. 




Figure 5. X-ray diffraction pattern for biosynthesized Ag NPs.

The FESEM images of the synthesized silver nanoparticles are shown in Figure 6 (a). The nanoparticles were found to be spherical, with particle sizes ranging from 10 to $80 \mathrm{~nm}$. Similarly, recent studies reported green synthesized nanoparticles with sizes ranging from 8 to $14 \mathrm{~nm}$ [19] and 18 to $30 \mathrm{~nm}$ [21] using aqueous leaf extract. The average diameter of the green synthesized Ag NPs was around $34.04 \mathrm{~nm}$ (average of 60 particles). The difference in particle size obtained by FESEM and DLS is due to the limited number of particles used for measurement, whereas DLS measure every particle in the sample. FESEM analysis showed relatively monodispersed particles in agreement with DLS and PDI value (0.3). The clustering of Ag NPs was observed in the FESEM image, possibly due to the sample preparation procedure. Nevertheless, there is no probability for particle aggregation or agglomeration as explained through the zeta potential value $-25.7 \mathrm{mV}$, representing high electrostatic repulsion among the particles and demonstrating a stable colloidal system. Elemental analysis of the silver nanoparticles conducted using EDAX on the FESEM is shown in Figure 6 (b). The peak around $3.2 \mathrm{keV}$ corresponds to the binding energies of silver, and the other peaks belong to the sputter-coated material and glass sample holder. It is evident from the results that the biosynthesized product is composed of high purity silver nanoparticles. These results confirm that basil seed extracts act as a capping agent and a reducing agent in forming silver nanoparticles.
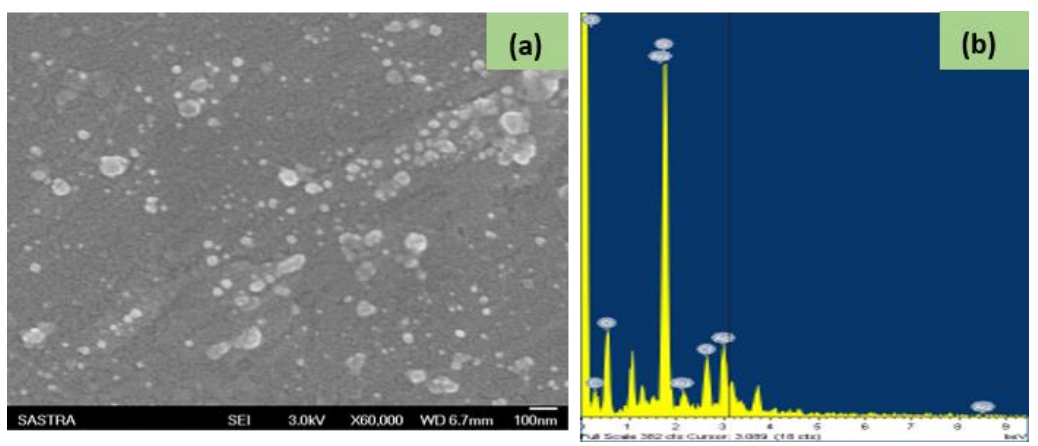

Figure 6. (a) FESEM analysis for biosynthesized Ag NPs; (b) EDAX analysis ofAg NPs.

\subsection{Antimicrobial activity.}

The antimicrobial activity of the biosynthesized Ag NPs was investigated against two different human pathogens, E. coli and S. aureus. Good antimicrobial activity against both microorganisms was evident (Figure 7). The zone of inhibition for both E. coli and S. aureus was around $10.33 \mathrm{~mm}$ and $7.2 \mathrm{~mm}$, respectively. The presence of peptidoglycan on the cell wall provides an effective barrier for bacteria. The reaction of Ag NPs with oxygen leads to 
the production of $\mathrm{Ag}^{+}$ions, resulting in cell disintegration by rupture of the cell wall [44]. The plasma membrane destabilization and rupture of the bacteria cell wall is responsible for cell death. The size of Ag NPs has an impact on their ability to destroy bacteria. Ag NPs give better contact with microorganisms due to their enhanced surface area to volume ratio. Smaller size particles can easily diffuse through the cell wall of the bacteria. Also, the particle's size directly impacts the surface area, reflects in binding level with the cell wall of the bacteria, and hinders the growth of bacteria [45]. Literature confirms these results that Ag NPs produced from plant extract showed strong inhibition of microbial action. It relies on the structural characteristic of nanoparticles, species, and concentration of the nanoparticles [46]. Nanosized particles allow penetration of silver ions easily into the bacterial cell and react with DNA molecule led to collapsing of DNA replication causes bacterial cell dysfunction [47]. Also, Ag NPs linked with the organosulfur compound of respiratory enzymes of the bacterial cell prevents the respiratory process and leads to cell death [48, 49]. Surface modification of orthopedic implants with Ag NPs showed a significant antimicrobial effect against implant-related infections [12]. Ag NPs have been extensively used in food packaging applications to improve shelf life and avoid microbial contamination [50]. No zone of inhibition was found in the case of the extract against E. coli, but a poor zone was formed against $S$. aureus.



Figure 7. Antibacterial activity gainst E.coli for (a) water; (b) extract; (c) Ag NPs and S. aureus for (d) water; (e) extract; (f) Ag NPs.

\subsection{Antioxidant activity.}

The free radical scavenging activity of the synthesized Ag NPs was assessed by the DPPH method. The DPPH solution exhibited a strong purple color with a maximum absorbance at $517 \mathrm{~nm}$. With the addition of Ag NPs, the deep purple color vanished, which could be attributed to the presence of antioxidants in the biosynthesized Ag NPs. Free radical scavenging activity of the seed extract and Ag NPs on the DPPH radical was found to be $54.0 \%$ and $76.1 \%$, respectively, while vitamin $\mathrm{C}$ exhibited $89.8 \%$ scavenging activity. Green synthesized Ag NPs using $O$. basilicum extract as a reducing agent exhibited higher free radical scavenging activity, and this could be a potential advantage for biomedical applications. Similar results with synthesized nanoparticles showing improved scavenging activity than the source plant extract have been reported by other researchers [51, 52].

\section{Conclusions}

This study shows that the basil seed extract can be an effective bioreducing agent for synthesizing silver nanoparticles. The reduced silver ions in basil seed extract showed maximum absorption at $430 \mathrm{~nm}$. Silver nanoparticles with an average diameter of $131.04 \mathrm{~nm}$ 
were spherical, and the zeta potential value was found to be around $-25.7 \mathrm{mV}$. The fair stability of Ag NPs was found to be because of the capping action of proteins in the basil seed extract. The Ag NPs synthesized in the green route exhibited high crystallinity with a face-centered cubic structure. Additionally, higher free radical scavenging activity, up to $76 \%$, and good antimicrobial action against harmful pathogenic microorganisms ( $S$. aureus and E. coli) explain its potential for biomedical applications. The approach is eco-friendly and cost-effective.

\section{Funding}

This research received no external funding.

\section{Acknowledgments}

This research has no acknowledgment.

\section{Conflicts of Interest}

The authors declare no conflict of interest.

\section{References}

1. Nair, L.; Laurencin, C. Silver Nanoparticles: Synthesis and Therapeutic Applications. Journal of Biomedical Nanotechnology 2007, 3, 301-316, https://doi.org/10.1166/jbn.2007.041.

2. Khandel, P.; Yadaw, R.K.; Soni, D.K.; Kanwar, L.; Shahi, S.K. Biogenesis of Metal Nanoparticles and Their Pharmacological Applications: Present Status and Application Prospects. Springer Berlin Heidelberg, Volume 8, 2018; https://doi.org/10.1007/s40097-018-0267-4.

3. Ghosh, B.; Ghosh, N. Applications of Metal Nanoparticles as Catalysts in Cleaning Dyes Containing Industrial Effluents: A Review. Journal of Nanoscience and Nanotechnology 2018, 18, 3735-3758, https://doi.org/10.1166/jnn.2018.15345.

4. Barsan, M.M.; Brett, C.M.A. Recent Advances in Layer-by-Layer Strategies for Biosensors Incorporating Metal Nanoparticles. TrAC Trends in Analytical Chemistry 2016, 79, 286-296, https://doi.org/10.1016/j.trac.2015.11.019.

5. Khan, Z.U.H.; Khan, A.; Chen, Y.; Shah, N.S.; Muhammad, N.; Khan, A.U.; Tahir, K.; Khan, F.U.; Murtaza, B.; Hassan, S.U.; Qaisrani, S.A.; Wan, P. Biomedical Applications of Green Synthesized Nobel Metal Nanoparticles. Journal of Photochemistry and Photobiology B: Biology 2017, 173, 150-164, https://doi.org/10.1016/j.jphotobiol.2017.05.034.

6. Sun-Waterhouse, D.; Waterhouse, G.I.N. 2 - Recent Advances in the Application of Nanomaterials and Nanotechnology in Food Research. In: Nanotechnology in the Agri-Food Industry. Grumezescu, A.M.B. Academic Press, 2016; pp. 21-66, https://doi.org/10.1016/B978-0-12-804308-0.00002-9.

7. Kowalska, E.; Endo, M.; Wei, Z.; Wang, K.; Janczarek, M. Chapter 21 - Noble Metal Nanoparticles for Water Purification. In: Micro and Nano Technologies. Thomas, S.; Pasquini, D.; Leu, S.-Y.; Gopakumar, D.A.B.T.N.M. Eds.; Elsevier, 2019; pp 553-579, https://doi.org/10.1016/B978-0-12-813926-4.00027-6.

8. George, J.M.; Antony, A.; Mathew, B. Metal Oxide Nanoparticles in Electrochemical Sensing and Biosensing: A Review. Microchimica Acta 2018, 185, https://doi.org/10.1007/s00604-018-2894-3.

9. Chhipa, H. Chapter 6 - Applications of Nanotechnology in Agriculture. In: Nanotechnology. Gurtler, V.; Ball, A.S.; Soni, S.B.T.-M. Eds.; Academic Press, Vulume 46, 2019; pp. 115-142, https://doi.org/10.1016/bs.mim.2019.01.002.

10. Thomas, S.W.; Khan, R.R.; Puttananjegowda, K.; Serrano-Garcia, W. Chapter 9 - Conductive Polymers and Metal Oxide Polymeric Composites for Nanostructures and Nanodevices. In: Advanced Nanomaterials. Guarino, V.; Focarete, M.L.; Pisignano, D.B.T.-A. Eds.; Elsevier, 2020; pp. 243-271, https://doi.org/10.1016/B978-0-12-816865-3.00009-3.

11. Carbone, M.; Donia, D.T.; Sabbatella, G.; Antiochia, R. Silver Nanoparticles in Polymeric Matrices for Fresh Food Packaging. Journal of King Saud University - Science 2016, 28, 273-279, https://doi.org/10.1016/j.jksus.2016.05.004.

12. Han, B.; Zhang, Y.-L.; Zhu, L.; Chen, X.-H.; Ma, Z.-C.; Zhang, X.-L.; Wang, J.-N.; Wang, W.; Liu, Y.-Q.; Chen, Q.-D.; Sun, H.-B. Direct Laser Scribing of AgNPs@RGO Biochip as a Reusable SERS Sensor for DNA Detection. Sensors and Actuators B: Chemical 2018, 270, 500-507, https://doi.org/10.1016/j.snb.2018.05.043. 
13. Qing, Y.; Cheng, L.; Li, R.; Liu, G.; Zhang, Y.; Tang, X.; Wang, J.; Liu, H.; Qin, Y. Potential Antibacterial Mechanism of Silver Nanoparticles and the Optimization of Orthopedic Implants by Advanced Modification Technologies. International journal of nanomedicine 2018, 13, 3311-3327, https://doi.org/10.2147/IJN.S165125.

14. Roy, A.; Bulut, O.; Some, S.; Mandal, A.K.; Yilmaz, M.D. Green Synthesis of Silver Nanoparticles: Biomolecule-Nanoparticle Organizations Targeting Antimicrobial Activity. RSC Adv. 2019, 9, 2673-2702, https://doi.org/10.1039/C8RA08982E.

15. Abdelghany, T.; Al-Rajhi, A.; Al Abboud, M.; Alawlaqi, M.; Ganash, M.; Helmy, E.; Mabrouk, A. Recent Advances in Green Synthesis of Silver Nanoparticles and Their Applications: About Future Directions. A Review. BioNanoScience 2017, 8, https://doi.org/10.1007/s12668-017-0413-3.

16. Alsammarraie, F. K.; Wang, W.; Zhou, P.; Mustapha, A.; Lin, M. Green Synthesis of Silver Nanoparticles Using Turmeric Extracts and Investigation of Their Antibacterial Activities. Colloids and Surfaces B: Biointerfaces 2018, 171, 398-405, https://doi.org/10.1016/j.colsurfb.2018.07.059.

17. Yaqoob, A.A.; Umar, K.; Ibrahim, M.N.M. Silver Nanoparticles: Various Methods of Synthesis, Size Affecting Factors and Their Potential Applications-a Review. Applied Nanoscience 2020, 10, 1369-1378, https://doi.org/10.1007/s13204-020-01318-w.

18. Rajput, S.; Kumar, D.; Agrawal, V. Green synthesis of silver nanoparticles using Indian Belladonna extract and their potential antioxidant, anti-inflammatory, anticancer and larvicidal activities. Plant Cell Reports 2020, 39, 921-939, https://doi.org/10.1007/s00299-020-02539-7.

19. Nouri, A.; Tavakkoli Yaraki, M.; Lajevardi, A.; Rezaei, Z.; Ghorbanpour, M.; Tanzifi, M. Ultrasonic-Assisted Green Synthesis of Silver Nanoparticles Using Mentha Aquatica Leaf Extract for Enhanced Antibacterial Properties and Catalytic Activity. Colloid and Interface Science Communications 2020, 35, https://doi.org/10.1016/j.colcom.2020.100252.

20. Aygün, A.; Özdemir, S.; Gülcan, M.; Cellat, K.; Şen, F. Synthesis and Characterization of Reishi MushroomMediated Green Synthesis of Silver Nanoparticles for the Biochemical Applications. Journal of Pharmaceutical and Biomedical Analysis 2020, 178, https://doi.org/10.1016/j.jpba.2019.112970.

21. Jebril, S.; Khanfir Ben Jenana, R.; Dridi, C. Green Synthesis of Silver Nanoparticles Using Melia Azedarach Leaf Extract and Their Antifungal Activities: In Vitro and in Vivo. Materials Chemistry and Physics 2020, 248, https://doi.org/10.1016/j.matchemphys.2020.122898.

22. Banasiuk, R.; Krychowiak, M.; Swigon, D.; Tomaszewicz, W.; Michalak, A.; Chylewska, A.; Ziabka, M.; Lapinski, M.; Koscielska, B.; Narajczyk, M.; Krolicka, A. Carnivorous Plants Used for Green Synthesis of Silver Nanoparticles with Broad-Spectrum Antimicrobial Activity. Arabian Journal of Chemistry 2020, 13, 1415-1428, https://doi.org/10.1016/j.arabjc.2017.11.013.

23. Renuka, R.; Devi, K. R.; Sivakami, M.; Thilagavathi, T.; Uthrakumar, R.; Kaviyarasu, K. Biosynthesis of Silver Nanoparticles Using Phyllanthus Emblica Fruit Extract for Antimicrobial Application. Biocatalysis and Agricultural Biotechnology 2020, 24, https://doi.org/10.1016/j.bcab.2020.101567.

24. Aisida, S.O.; Ugwu, K.; Akpa, P.A.; Nwanya, A.C.; Ejikeme, P.M.; Botha, S.; Ahmad, I.; Maaza, M.; Ezema, F.I. Biogenic Synthesis and Antibacterial Activity of Controlled Silver Nanoparticles Using an Extract of Gongronema Latifolium. Materials Chemistry and Physics 2019, 237, https://doi.org/10.1016/j.matchemphys.2019.121859.

25. Osano, J.P.; Hosseini-Parvar, S.H.; Matia-Merino, L.; Golding, M. Emulsifying Properties of a Novel Polysaccharide Extracted from Basil Seed (Ocimum Bacilicum L.): Effect of Polysaccharide and Protein Content. Food Hydrocolloids 2014, 37, 40-48, https://doi.org/10.1016/j.foodhyd.2013.09.008.

26. Sestili, P.; Ismail, T.; Calcabrini, C.; Guescini, M.; Catanzaro, E.; Turrini, E.; Layla, A.; Akhtar, S.; Fimognari, C. The Potential Effects of Ocimum Basilicum on Health: A Review of Pharmacological and Toxicological Studies. Expert Opinion on Drug Metabolism \& Toxicology 2018, 14, 679-692, https://doi.org/10.1080/17425255.2018.1484450.

27. Gajendiran, A.; Thangaraman, V.; Thangamani, S.; Ravi, D.; Abraham, J.J.B.o.P.R. Antimicrobial, antioxidant and anticancer screening of Ocimum basilicum seeds. Bulletin of Pharmaceutical Research 2016, 6, 114-119. https://doi.org/10.21276/bpr.2016.6.3.5.

28. Balakrishnan, P.; Ramalingam, P.; Nagarasan, S.; Ranganathan, B.; Gimbun, J.; Shanmugam, K. A Comprehensive Review on Ocimum Basilicum. Journal of Natural Remedies 2018, 18, 71-85, https://doi.org/10.18311/jnr/2018/21324.

29. Bucktowar, K.; Bucktowar, S.; Bucktowar, M.; Bholoa, L.D. Formulation and Evaluation of Fast Dissolving Tablets of Paracetamol Using Ocimum Basilicum Seed Mucilage as Superdisintegrant. International Research Journal of Pharmaceutical and Bioscience 2017, 4, 44-55.

30. Parikh, H.; Kothari, C. Phytochemical Analysis and Total Phenolic and Flavonoid Contents Determination of Methanolic Extract of Ocimum Basilicum L Seed. International Journal of PharmTech Research 2016, 9 , 215-219.

31. Manosalva, N.; Tortella, G.; Cristina Diez, M.; Schalchli, H.; Seabra, A. B.; Durán, N.; Rubilar, O. Green Synthesis of Silver Nanoparticles: Effect of Synthesis Reaction Parameters on Antimicrobial Activity. World Journal of Microbiology and Biotechnology 2019, 35, https://doi.org/10.1007/s11274-019-2664-3. 
32. Haque, B.M.; Chandra, D.B.; Jiban, P.; Nurul, I.; Abdullah, Z. Influence of Fe2+/Fe3+ Ions in Tuning the Optical Band Gap of SnO2 Nanoparticles Synthesized by TSP Method: Surface Morphology, Structural and Optical Studies. Materials Science in Semiconductor Processing 2019, 89, 223-233, https://doi.org/10.1016/j.mssp.2018.09.023.

33. Raghavi, L.M.; Moses, J.A.; Anandharamakrishnan, C. Refractance Window Drying of Foods: A Review. Journal of Food Engineering 2018, 222, 267-275, https://doi.org/10.1016/j.jfoodeng.2017.11.032.

34. Yoha, K.S.; Moses, J.A.; Anandharamakrishnan, C. Conductive Hydro Drying through Refractance Window Drying - An Alternative Technique for Drying of Lactobacillus Plantarum (NCIM 2083). Drying Technology 2020, 38, 610-620, https://doi.org/10.1080/07373937.2019.1624972.

35. Amirjani, A.; Fatmehsari, D.H. Colorimetric Detection of Ammonia Using Smartphones Based on Localized Surface Plasmon Resonance of Silver Nanoparticles. Talanta 2018, 176, 242-246, https://doi.org/10.1016/j.talanta.2017.08.022.

36. Vijayan, R.; Joseph, S.; Mathew, B. Indigofera Tinctoria Leaf Extract Mediated Green Synthesis of Silver and Gold Nanoparticles and Assessment of Their Anticancer, Antimicrobial, Antioxidant and Catalytic Properties. Artificial Cells, Nanomedicine, and Biotechnology 2018, 46, 861-871, https://doi.org/10.1080/21691401.2017.1345930.

37. Femi-Adepoju, A.G.; Dada, A.O.; Otun, K.O.; Adepoju, A.O.; Fatoba, O.P. Green Synthesis of Silver Nanoparticles Using Terrestrial Fern (Gleichenia Pectinata (Willd.) C. Presl.): Characterization and Antimicrobial Studies. Heliyon 2019, 5, https://doi.org/10.1016/j.heliyon.2019.e01543.

38. El-Kemary, M.; El-Shamy, H. Fluorescence Modulation and Photodegradation Characteristics of Safranin O Dye in the Presence of ZnS Nanoparticles. Journal of Photochemistry and Photobiology A: Chemistry 2009, 205, 151-155, https://doi.org/10.1016/j.jphotochem.2009.04.021.

39. Aisida, S.O.; Ugwu, K.; Nwanya, A.C.; Bashir, A.K.H.; Uba Nwankwo, N.; Ahmed, I.; Ezema, F.I. Biosynthesis of silver oxide nanoparticles using leave extract of Telfairia Occidentalis and its antibacterial activity. Materials Today: Proceedings 2021, 36, 208-213, https://doi.org/10.1016/j.matpr.2020.03.005.

40. Nindawat, S.; Agrawal, V. Fabrication of Silver Nanoparticles Using Arnebia Hispidissima (Lehm.) A. DC. Root Extract and Unravelling Their Potential Biomedical Applications. Artificial Cells, Nanomedicine, and Biotechnology 2019, 47, 166-180, https://doi.org/10.1080/21691401.2018.1548469.

41. Tripathi, D.; Modi, A.; Narayan, G.; Rai, S.P. Green and Cost Effective Synthesis of Silver Nanoparticles from Endangered Medicinal Plant Withania Coagulans and Their Potential Biomedical Properties. Materials Science and Engineering C 2019, 100, 152-164, https://doi.org/10.1016/j.msec.2019.02.113.

42. Asimuddin, M.; Shaik, M.R.; Adil, S.F.; Siddiqui, M.R.H.; Alwarthan, A.; Jamil, K.; Khan, M. Azadirachta indica based biosynthesis of silver nanoparticles and evaluation of their antibacterial and cytotoxic effects. Journal of King Saud University - Science 2020, 32, 648-656, https://doi.org/10.1016/j.jksus.2018.09.014.

43. Chand, K.; Abro, M.I.; Aftab, U.; Shah, A.H.; Lakhan, M.N.; Cao, D.; Mehdi, G.; Mohamed, A.M.A. Green synthesis characterization and antimicrobial activity against Staphylococcus aureus of silver nanoparticles using extracts of neem, onion and tomato. RSC advances 2019, 9, 17002-17015, https://doi.org/10.1039/C9RA01407A.

44. Guimarães, M.; Silva, F.; Costa, M.; Oliveira, H. Green Synthesis of Silver Nanoparticles Using Ziziphus Joazeiro Leaf Extract for Production of Antibacterial Agents. Applied Nanoscience 2019, 10, https://doi.org/10.1007/s13204-019-01181-4.

45. Siddiqi, K.; Husen, A.; Rao, R. A Review on Biosynthesis of Silver Nanoparticles and Their Biocidal Properties. Journal of Nanobiotechnology 2018, 16, https://doi.org/10.1186/s12951-018-0334-5.

46. Tanase, C.; Berța, L.; Mare, A.; Man, A.; Talmaciu, A.; Roșca, I.; Mircia, E.; Volf, I.; Popa, V. Biosynthesis of Silver Nanoparticles Using Aqueous Bark Extract of Picea Abies L. and Their Antibacterial Activity. European Journal of Wood and Wood Products 2020, 78, https://doi.org/10.1007/s00107-020-01502-3.

47. Xueting, Y.; He, B.; Liu, L.; Qu, G.; Shi, J.; Hu, L.; Jiang, G. Antibacterial Mechanism of Silver Nanoparticles in Pseudomonas Aeruginosa: Proteomics Approach. Metallomics 2018, 10, https://doi.org/10.1039/C7MT00328E.

48. Durán, N.; Durán, M.; de Jesus, M.B.; Seabra, A.B.; Fávaro, W.J.; Nakazato, G. Silver Nanoparticles: A New View on Mechanistic Aspects on Antimicrobial Activity. Nanomedicine: Nanotechnology, Biology and Medicine 2016, 12, 789-799, https://doi.org/10.1016/j.nano.2015.11.016.

49. Koduru, J. R.; Kailasa, S. K.; Bhamore, J. R.; Kim, K. H.; Dutta, T.; Vellingiri, K. Phytochemical-Assisted Synthetic Approaches for Silver Nanoparticles Antimicrobial Applications: A Review. Advances in Colloid and Interface Science 2018, 256, 326-339, https://doi.org/10.1016/j.cis.2018.03.001.

50. Lee, S.H.; Jun, B.H. Silver Nanoparticles: Synthesis and Application for Nanomedicine. International Journal of Molecular Sciences 2019, 20, 1-23, https://doi.org/10.3390/ijms20040865.

51. Phull, A.-R.; Abbas, Q.; Ali, A.; Raza, H.; kim, S. J.; Zia, M.; Haq, I. Antioxidant, Cytotoxic and Antimicrobial Activities of Green Synthesized Silver Nanoparticles from Crude Extract of Bergenia Ciliata. Future Journal of Pharmaceutical Sciences 2016, 2, 31-36, https://doi.org/10.1016/j.fjps.2016.03.001.

52. Keshari, A.K.; Srivastava, R.; Singh, P.; Yadav, V.B.; Nath, G. Antioxidant and Antibacterial Activity of Silver Nanoparticles Synthesized by Cestrum Nocturnum. Journal of Ayurveda and Integrative Medicine 2020, 11, 37-44, https://doi.org/10.1016/j.jaim.2017.11.003. 